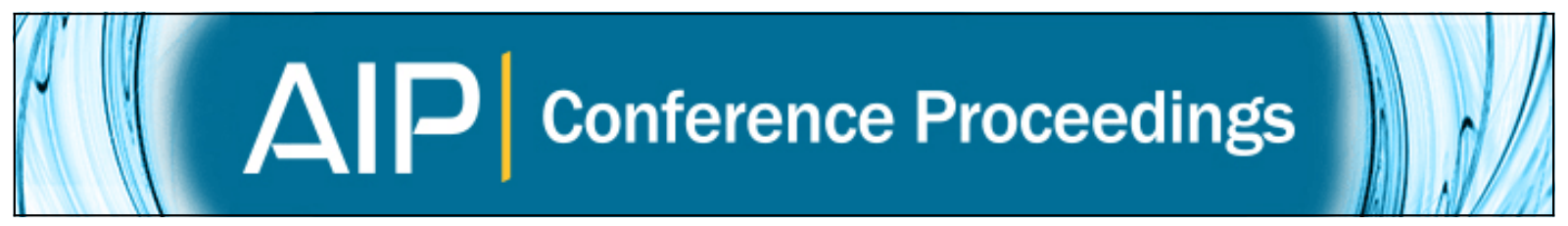

\title{
Chemistry of stabilized Criegee intermediates in the CLOUD chamber
}

Nina Sarnela, Mikko Sipilä, Tuija Jokinen, Heikki Junninen, and CLOUD Collaboration

Citation: AIP Conference Proceedings 1527, 381 (2013); doi: 10.1063/1.4803283

View online: http://dx.doi.org/10.1063/1.4803283

View Table of Contents: http://scitation.aip.org/content/aip/proceeding/aipcp/1527?ver=pdfcov

Published by the AIP Publishing

\section{Articles you may be interested in}

Threshold photoelectron spectroscopy of unstable $\mathrm{N}$-containing compounds: Resolution of $\Delta \mathrm{K}$ subbands in $\mathrm{HNCO}+$ and vibrational resolution in $\mathrm{NCO}+$

J. Chem. Phys. 142, 184306 (2015); 10.1063/1.4920951

Aerosol nucleation and growth in a mixture of sulfuric acid/alpha-pinene oxidation products at the CERN CLOUD chamber

AIP Conf. Proc. 1527, 322 (2013); 10.1063/1.4803268

Modelling new particle formation from Jülich plant atmosphere chamber and CERN CLOUD chamber measurements

AIP Conf. Proc. 1527, 173 (2013); 10.1063/1.4803231

Discharge flow tube coupled to time-of-flight mass spectrometry detection for kinetic measurements of interstellar and atmospheric interests

Rev. Sci. Instrum. 76, 053105 (2005); 10.1063/1.1898727

Simultaneous in situ detection of atmospheric NO 3 and N 2 O 5 via cavity ring-down spectroscopy

Rev. Sci. Instrum. 73, 3291 (2002); 10.1063/1.1499214 


\title{
Chemistry of Stabilized Criegee Intermediates in the CLOUD Chamber
}

\author{
Nina Sarnela ${ }^{\mathrm{a}}$, Mikko Sipilä ${ }^{\mathrm{a}}$, Tuija Jokinen ${ }^{\mathrm{a}}$, Heikki Junninen ${ }^{\mathrm{a}}$ and the \\ CLOUD collaboration
}

${ }^{a}$ University of Helsinki, Department of Physics, P.O. Box 64, 00014 University of Helsinki, Finland

\begin{abstract}
In atmospheric conditions the oxidation of sulphur dioxide to sulphuric acid in gas phase has been considered to be determined by the concentration of hydroxyl radical. Recently the significance of stabilized Criegee intermediate as an oxidizer of sulphuric acid has been brought out. In this study we investigated the oxidation of sulphur dioxide in the CLOUD chamber in conditions where the hydroxyl radical was removed. The concentration of formed sulphuric acid was measured with a chemical ionization atmospheric pressure interface time-offlight mass spectrometer and it was compared with the calculated yield of sulphuric acid.
\end{abstract}

Keywords: $\alpha$-pinene ozonolysis, stabilized Criegee intermediates, chamber experiment PACS: $92.60 \mathrm{Mt}, 82.33 \mathrm{~Tb}$

\section{INTRODUCTION}

Oxidation of trace gases is an important but yet unclear part of the atmospheric chemistry. Until recently the understanding has been that the main oxidants are hydroxyl radical $\left(\mathrm{OH}^{*}\right)$, ozone $\left(\mathrm{O}_{3}\right)$ and nitrate radical $\left(\mathrm{NO}_{3}{ }^{\circ}\right)^{1}$, hydroxyl radical dominating during the daytime and nitrate radical during the night. The oxidation of sulphur dioxide has been determined by the concentration of $\mathrm{OH}$ but the measurements have implied that there is not enough $\mathrm{OH}$ to produce all the oxidation products that had been detected ${ }^{2}$. Lately the importance of the stabilized Criegee intermediate $(\mathrm{sCI})$ as an oxidizer of $\mathrm{SO}_{2}$ has been under discussion ${ }^{3}$.

The sCI forms in the gas-phase reaction between ozone and olefin (Figure 1). In our study we produced sCI using $\alpha$-pinene as a precursor it being one of the most abundant monoterpenes in the atmosphere especially in the boreal forest. Sulphuric acid is a key compound in the initial step of new particle formation so its formation from sulphur dioxide by an oxidation reaction has a significant role in atmospheric chemistry.

In this study we investigated the ability of sCI to oxidize $\mathrm{SO}_{2}$ in well-defined conditions of CLOUD chamber. We calculated the amount of sCI produced by the precursors and the concentration of sulphuric acid formed from the reaction of $\mathrm{sCI}$ with $\mathrm{SO}_{2}$. 


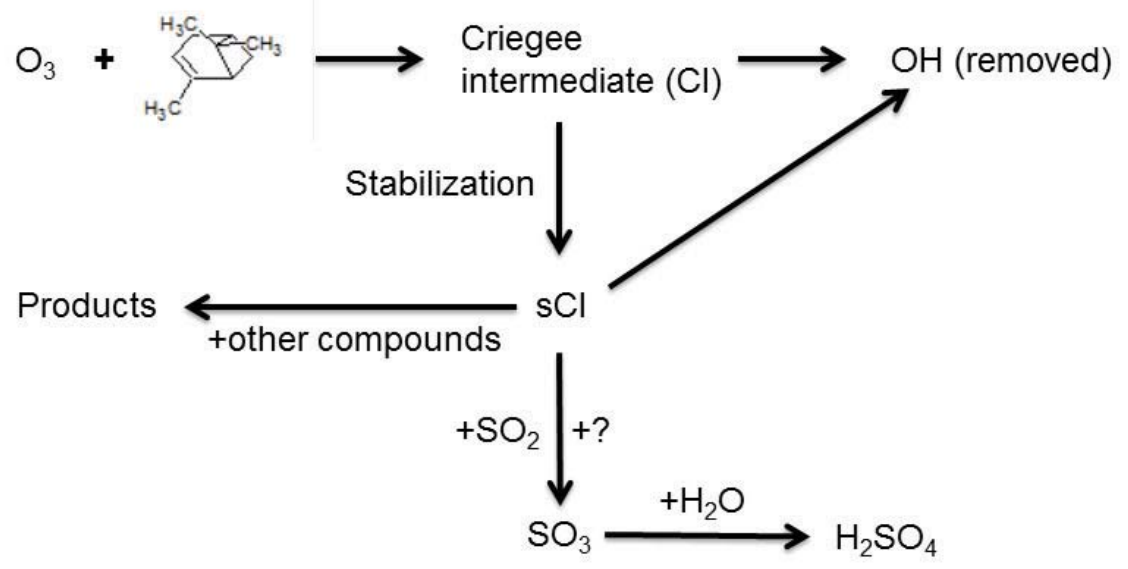

FIGURE 1. Proposed mechanism for the formation of the stabilized Criegee intermediate from ozone and $\alpha$-pinene ${ }^{1}$. In CLOUD experiments produced $\mathrm{OH}$ was scavenged by adding hydrogen into the chamber.

\section{METHODS}

The steady state concentration of stabilized Criegee intermediates produced from $\alpha$ pinene and ozone is defined in Eq. 1 where $Y$ equals the yield of sCI, $k_{l}$ is the rate coefficient and $k_{\text {loss }}$ is the inverse of the lifetime of the sCI, dominated by the thermal decomposition of SCI in the sub-second time scale ${ }^{3}$.

$$
[s C I]=\frac{Y \cdot k_{1} \cdot\left[O_{3}\right] \cdot[\alpha-\text { pinene }]}{k_{\text {loss }}}
$$

The steady state concentration of sulphuric acid produced by sCI is calculated according to the Eq. 2 where $k_{2}$ stands for the rate coefficient of the reaction between $\mathrm{sCI}$ and $\mathrm{SO}_{2}$ and $W L$ is the wall loss rate for sulphuric acid.

$$
\left[\mathrm{H}_{2} \mathrm{SO}_{4}\right]=\frac{k_{2} \cdot[\mathrm{SCI}] \cdot\left[\mathrm{SO}_{2}\right]}{W L}
$$

The values for rate coefficient $k_{2}, Y$ and $k_{\text {loss }}$ have been determined experimentally in Leibniz-Institute for Tropospheric Research ${ }^{4}$.

The CLOUD (Cosmics Leaving OUtdoor Droplets) chamber is an advanced laboratory setup located in CERN that is used to study the formation and growth of aerosol particles ${ }^{5}$. We investigated gas-phase ozonolysis experiments for $\alpha$-pinene in the CLOUD chamber in the autumn 2012. These sCI measurements were done in neutral conditions using high electric fields to remove formed ions from the chamber. During these measurements the concentration of $0.1 \% \mathrm{H}_{2}$ was added to the chamber to work as an $\mathrm{OH}$-scavenger. $\mathrm{OH}$ was removed using this technique and the only oxidizer left in the chamber was $\mathrm{O}_{3}$. The concentration of ozone was kept constant during measurements while the concentration of $\alpha$-pinene varied between $100 \mathrm{ppt}$ and 1600 
ppt. The concentration of $\mathrm{SO}_{2}$ was around 63-72 ppb for all the experiments except one test with lower concentration (17 ppb). All the experiments were done at $\sim 278 \mathrm{~K}$. The sulphuric acid concentration was measured by Atmospheric Pressure interface Time Of Flight mass spectrometer that had an x-ray Chemical Ionization inlet (CIAPi-TOF $)^{6,7}$.

\section{RESULTS}

When calculating the concentration of sulphuric acid produced by sCI only the wall loss of sulphuric acid was taken into account so the loss of sulphuric acid into clusters and particles is probably one reason causing the differences between measured and calculated values. Bearing those losses in mind the measured sulphuric acid concentrations match the range of the calculated ones (Figure 2). Other sources of error in calculated and measured values include differences in temperature and maybe concentrations of gases - including $\mathrm{SO}_{2}$ and $\mathrm{H}_{2} \mathrm{O}$ - between the present and the previous ${ }^{4}$ study. Nevertheless, these results support the range of experimentally achieved values for $k_{2}, Y$ and $k_{\text {loss }}$ and highlight the importance of sCI as an atmospheric oxidizer.

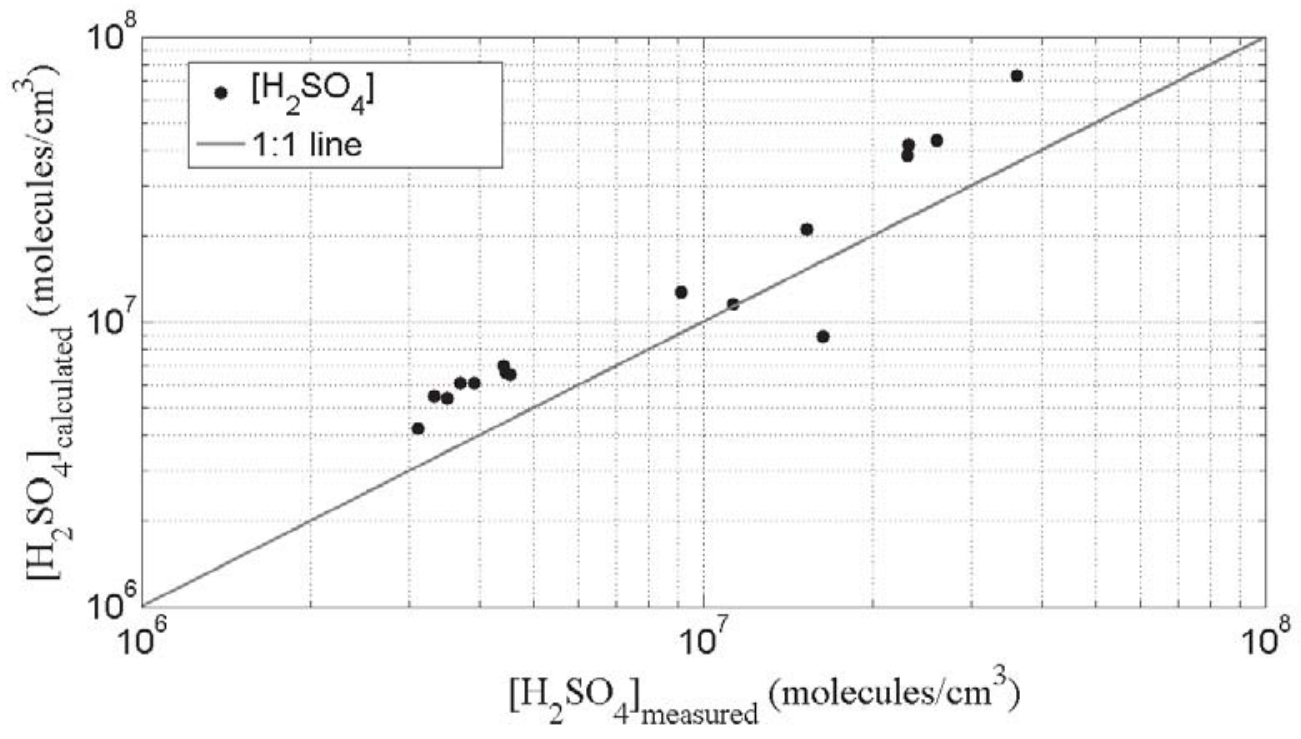

FIGURE 2. Calculated sCI produced sulphuric acid concentrations as a function of the measured concentrations. 


\section{ACKNOWLEDGMENTS}

Acknowledgements: We would like to thank CERN for supporting CLOUD with important technical and financial resources, and for providing a particle beam from the CERN Proton Synchrotron. This research has received funding from the EC Seventh Framework Programme (Marie Curie Initial Training Network "CLOUD-ITN" no. 215072, MC-ITN "CLOUD-TRAIN" no. 316662, and ERC-Advanced "ATMNUCLE" grant no. 227463), the German Federal Ministry of Education and Research (project nos. 01LK0902A and 01LK1222A), the Swiss National Science Foundation (project nos. 200020_135307 and 206620_130527), the Academy of Finland (Center of Excellence project no. 1118615), the Academy of Finland (135054, 133872, 251427, 139656, 139995, 137749, 141217, 141451), the Finnish Funding Agency for Technology and Innovation, the Nessling Foundation, the Austrian Science Fund (FWF; project no. P19546 and L593), the Portuguese Foundation for Science and Technology (project no. CERN/FP/116387/2010), the Swedish Research Council, Vetenskapsrådet (grant 2011-5120), the Presidium of the Russian Academy of Sciences and Russian Foundation for Basic Research (grants 08-02-91006-CERN and 12-02-91522-CERN), and the U.S. National Science Foundation (grants AGS1136479 and CHE1012293).

\section{REFERENCES}

1. R. L. Mauldin III, T. Berndt, M. Sipilä, P. Paasonen, T. Petäjä, S. Kim, T. Kurten, F. Strantmann, V.-M. Kerminen and M. Kulmala, Nature, 488, 193-196 (2012).

2. P. Di Carlo, W. H. Brune, M. Martinez, H. Harder, R. Lesher, X. R. Ren, T. Thornberry, M. A. Carroll, V. Young, P. B. Shepson, D. Riemer, E. Apel, and C. Campbell, Science, 304, 722-725 (2004).

3. T. Berndt, T. Jokinen, R. L. Mauldin III, T. Petäjä, H. Herrmann, H. Junninen, P. Paasonen, D. R. Worsnop and M. Sipilä, J. Phys. Chem. Lett. 3, 2892-2896 (2012)

4. M. Sipilä et al, these proceedings.

5. J. Kirkby et al, Nature, 476, 429-433 (2011)

6. T. Jokinen, M. Sipilä, H. Junninen, M. Ehn, G. Lönn, J. Hakala, T. Petäjä, R. L. Mauldin III, M. Kulmala and D. R. Worsnop, Atmos. Chem. Phys. 12, 4117-4125 (2012)

7. H. Junninen, M. Ehn, T. Petäjä, L. Luosujärvi, T. Kotiaho, R. Koistinen, U. Rohner, M. Gonin, K. Fuhrer, M. Kulmala and D. R. Worsnop, Atmos. Meas. Tech. 3, 1039-1053 (2010) 